\title{
Considerações sobre a expansão capitalista para o semiárido
}

\author{
Erlene Pereira Barbosa \\ Universidade Federal do Ceará ${ }^{1}$ \\ Wagner Pires da Silva \\ Universidade Federal de Pelotas ${ }^{2}$
}

Resumo: Este trabalho procura entender a formação e os aspectos humanos e sociais que compõem o semiárido, traçando, sob um viés antropológico, um esboço do que é o semiárido, que engloba a maior parte do território nordestino, realizando uma discussão que possibilite a compreensão do local no imaginário social. O sertão nordestino abriga milhões de indivíduos, sendo um território rico em cultura e costumes com características próprias bem diversas de outras regiões e que nas últimas décadas tem recebido transformações agudas em suas relações de trabalho. Utilizando a abordagem marxista é possível acompanhar as transformações locais e suas relações com o global em um momento em que se alargam as fronteiras econômicas, com o capitalismo e a globalização moldando a rotina das pessoas, mesmo nos lugares mais remotos.

Palavras-chave: Semiárido; Expansão capitalista; Trabalho.

\section{Considerations about capitalist expansion to the Semi-arid}

Abstract: This paper seeks to understand the formation and the buman and social aspects that make up the semiarid region, outlining, from an anthropological point of view, what the semi-arid region is, which encompasses most of the territory of the Northeast of Brazil, holding a discussion that makes it possible to understand the local character in the social imaginary. The backlands of the Northeast are home to millions of individuals, a territory rich in culture and customs with its own characteristics that are quite different from those of other regions. Using a Marxist approach it is possible to follow the local transformations and their relations with the global in a moment when the economic frontiers are widening, with capitalism and globalization shaping the routine of people even in the most remote places.

Keywords: Semi-arid; Capitalist expansion; Work.

\footnotetext{
1 Graduanda em Ciências Sociais pela Universidade Federal do Ceará. Pedagoga pela FACED/Itapipoca da Universidade Estadual do Ceará. ORCiD: https://orcid.org/0000-0002-2477-7848, E-mail: erlene2013@gmail.com

2 Doutorando em Educação na Universidade Federal de Pelotas. Mestre em políticas Públicas e Gestão da Educação Superior pela Universidade Federal do Ceará. ORCiD: https://orcid.org/0000-0002-7229-0655. Email: wagner.pires@ufpel.edu.br
}

Cadernos GPOSSHE On-line, Fortaleza, v. 5, n. 1, 2021

https://revistas.uece.br/index.php/CadernosdoGPOSSHE

DOI: $10.33241 /$ cadernosdogposshe.v5i1

ISSN: $2595-7880$ 


\section{INTRODUÇÃO}

Nordeste não é apenas um espaço geográfico, e entendê-lo dessa forma é o primeiro passo para compreendê-lo no complexo contexto em que ele se insere. De acordo com Albuquerque Jr. (2011), a formulação de uma ideia de Nordeste é resultado do agrupamento de experiências que caracterizam o espaço e a identidade regional. A primeira constatação a ser feita é que essa região simplesmente não existia durante boa parte da história brasileira, sendo conhecida apenas por Norte ou, ainda, sertões do Norte (ALBUQUERQUE JR., 2011). Mesmo a delimitação do Nordeste foi um processo volúvel, em que alguns estados nordestinos, por vezes, nem foram considerados como parte da região, quando esse começou a ganhar forma. Houve, segundo o autor, um esforço de invenção da mesma e de sua gente:

O nexo de conhecimento e poder que cria o nordestino e, ao mesmo tempo, o oblitera como ser humano. O Nordeste não é recortado só como uma unidade econômica, política ou geográfica, mas, primordialmente, como um campo de estudos e produção cultural, baseado numa pseudo-unidade cultural geográfica e étnica (ALBUQUERQUE JR, 2011, p. 33)

Para Albuquerque Jr. (2011) o Nordeste foi construído para manter uma estrutura de poder. Nessa estrutura busca-se homogeneizar seu povo e apagar as suas diferenças, objetivando facilitar a dominação da maioria, formada por camponeses e trabalhadores urbanos, pela elite em seu projeto de perpetuar-se no poder. Investe-se em uma narrativa que procura mostrar o Nordeste como uma região-problema, onde as características naturais, como as secas impedem o desenvolvimento.

O Nordeste seria “[...] uma produção imagético-discursiva formada a partir de uma sensibilidade cada vez mais específica, gestada historicamente em relação a uma dada área do país” (ALBUQUERQUE JR, 2011, p. 62). Essa “invenção” relegou aos trabalhadores um papel caricato e submisso, sempre à espera de uma solução oriunda de fora da região e de sua classe, negando a rebeldia, que, segundo Garcia (1999), sempre caracterizou as populações do Nordeste.

Uma consideração a ser feita ao se estudar o Nordeste é que o mesmo, diferente do discurso que se faz sobre ele, não é uma região homogênea, "é uma região de contrastes" (GARCIA, 1999, p. 08). O autor destaca que se pode falar de quatro regiões naturais do 
Nordeste: a Mata, o Agreste, o Sertão (o semiárido se estende por essas duas regiões) e o Meio-Norte.

A denominada Zona da Mata, que se estende pela costa desde o Rio Grande do Norte até a Bahia, região de clima mais ameno, com chuvas regulares, onde se concentram as principais lavouras nordestinas, bem como boa parte do parque industrial. O Agreste seria uma zona de transição entre a Mata e o Sertão, e, embora integre o semiárido, possui índices de chuva mais altos e regulares que o Sertão. Este equivale a mais da metade do território nordestino, costuma ser chamado de Nordeste seco, em contraste com o Nordeste úmido representado pelas regiões com maior volume de chuvas. Já o Meio-Norte é uma zona de transição entre o Nordeste seco e a Amazônia, compreendendo todo o Maranhão e parte do Piauí (GARCIA, 1999).

Marcado no imaginário nacional pelas secas, como já dito anteriormente, o Nordeste é bem mais do que isso e se constitui, nos últimos tempos, em um espaço considerável para a expansão capitalista em sua busca por acumulação, tanto pela mão de obra disponível a baixo custo quanto para o potencial consumidor da população que habita o território.

\section{AS POLÍTICAS DE COMBATE ÀS SECAS E AS DE CONVIVÊNCIA COM O SEMIÁRIDO}

O Nordeste foi uma das regiões mais dinâmicas e centrais do Brasil, chegando a ser o principal motor da economia brasileira durante o Período Colonial e o Primeiro Império, com um breve interregno do Ciclo do Ouro. Com a centralização do poder político no Rio de Janeiro e a ascensão da hegemonia da cafeicultura, a região foi sendo relegada a segundo plano.

A partir daí o Centro-Sul passou a experimentar grande modernização, enquanto o Nordeste mantinha sua estrutura rural arcaica e sua industrialização limitava-se praticamente às grandes centrais açucareiras e às fábricas de tecidos. Esse contraste passou então a gerar um quadro cada vez maior de desigualdade econômica entre as duas regiões (GARCIA, 1999, p. 31).

Ainda que deixasse de ser um centro da economia brasileira, cedendo lugar ao Centro-Sul, com o início do chamado Ciclo do Ouro, e depois com o café, de acordo com Buarque (2001), o Nordeste não se tornou uma região pobre, nem era visto enquanto 
problema. A visão acerca do Nordeste começou a mudar a partir da década de 1870, quando as secas começaram a chamar a atenção do poder central. A partir desse evento, o Nordeste passa a ser visto como a ser visto como um problema decorrente das condições naturais e climáticas, que geravam a estiagem, a escassez de água e a pobreza dos solos. Esse discurso era a ideia central de um diagnóstico para a região que foi construído para cumprir com o objetivo de acobertar:

(...) as formas dominantes da exploração econômica que criaram e reproduziram a concentração das riquezas e do poder político, gerando miséria e dependência de milhares de sertanejos. A concentração fundiária e a exploração da mão-deobra dos sertanejos têm destaque na explicação da manutenção da miséria na região semiárida (SILVA, 2003, p. 362).

Munidos dessa formulação, apontava-se como solução dos problemas do Nordeste a utilização de certas técnicas de engenharia, tais como o represamento das águas, entre outras. Para tanto, explica Buarque (2011), foi criado o Inspetoria Federal de Obras Contra as Secas (IFOCS), tão longevo, mesmo com a constante ameaça de fechamento pelos governos liberais, ele chega ao século XXI com a atual denominação de Departamento Nacional de Obras Contra as Secas (DNOCS). No entanto, como vimos, o Nordeste não é só o semiárido, e mesmo o semiárido não tem seus problemas como o resultado de uma natureza imprópria. Ora, se "[...] o modo de produção da vida material condiciona o processo em geral de vida social, político e espiritual” (MARX, 1986, p. 25), pressupõe-se, como se verá adiante, que os problemas do Nordeste se relacionam ao desenvolvimento das forças produtivas do território, o que demanda a superação desse atraso, mas não está entre os interesses por parte das elites locais e nacionais a alteração da estrutura de produção da região.

Dito isso, é preciso reconhecer que no Nordeste úmido as capitais se encontravam em um patamar de desenvolvimento diferente do semiárido. E embora as políticas públicas, os governantes e as elites insistissem em rotular a região como homogênea, eram visíveis as diferenças entre o semiárido e as áreas mais desenvolvidas da região. O presente trabalho mantém seu foco no semiárido, território em que se dá a partir dos fins do século XX uma acelerada integração ao sistema capitalista brasileiro e mundial.

O conjunto de práticas pensadas para resolver os problemas do Nordeste constituiu um paradigma conhecido como de combate às secas. Eram soluções, para as dificuldades 
dos sertanejos, que vinham de fora da região, sem se importarem com a cultura e os saberes da população que buscava ajudar. Para além disso:

O combate às secas também utiliza políticas de estímulo à migração da população do semiárido para outras regiões, constituindo um exército de reserva que barateava o valor da mão-de-obra para as indústrias e o agronegócio dos territórios que recebiam esse êxodo (BARBOSA ET ALL, 2018, p. 63).

As medidas de combate às secas foram as primeiras políticas públicas voltadas para o semiárido. Infelizmente, como percebiam o interior do Nordeste como uma regiãoproblema, acabavam por considerar a região como um território que não possui nem produz conhecimento, onde o povo era atrasado e não possuía educação, justificando a imposição da resolução de seus problemas vinda de fora da região e mesmo do estímulo ao êxodo para outras regiões (BAPTISTA; CAMPOS, 2013).

Interessante notar que o estímulo ao êxodo para outras regiões era importante num momento em que a burguesia brasileira precisava montar um exército de reserva para os empreendimentos capitalistas que se desenvolviam no eixo Sul-Sudeste, como forma de baratear a mão de obra. Como explica Harvey:

\begin{abstract}
A acumulação do capital, na ausência de fortes correntes de mudança tecnológica poupadora de trabalho, requer o aumento da força de trabalho, que pode acontecer de várias maneiras. $\mathrm{O}$ aumento da população é importante (e a maioria dos analistas esquece convenientemente os cuidados que o próprio Marx tomou quanto a isso). O capital também pode se apropriar de "reservas latentes" de um campesinato ou, por extensão, mobilizar mão-de-obra barata de colônias e outros ambientes externos (HARVEY, 2005, P.118).
\end{abstract}

O combate às secas não buscava estimular a ruptura com as práticas seculares de poder das oligarquias, e sim as fortalecia, o que levava a muitos dos pesquisadores do tema a ver a implementação do capitalismo como a solução para a região. Djacir de Menezes (2018), em livro sobre o Nordeste seco, escrito em 1937, é categórico em afirmar que:

(...) o estabelecimento de relações capitalistas de trabalho no território, "o incessante desenvolvimento das forças de produção, o comércio internacional, o sistema "casagrande e senzala" se vai esfacelando (...) com a aparição do urbanismo industrial, das firmas comerciais nos centros citadinos, as senzalas enfraquecem, aumentam as populações dos mocambos, multiplicam-se os braços

Cadernos GPOSSHE On-line, Fortaleza, v. 5, n. 1, 2021

https://revistas.uece.br/index.php/CadernosdoGPOSSHE

DOI: $10.33241 /$ cadernosdogposshe.v5i1

ISSN: $2595-7880$ 
salariados; e desloca-se a importância dos senhores rurais para o industrialismo nascente. Decompõe-se o patriarcalismo (MENEZES, 2018, p.107)

A oposição das elites a esse processo pode ser sentida na análise da literatura do Nordeste de meados do século XX, em que as obras dos representantes da oligarquia tradicional relatam, por um viés negativo, a desagregação dos engenhos e do poder das oligarquias pelo estabelecimento de empreendimentos capitalistas, tal como mostra Albuquerque Jr. (2011). O sistema capitalista acomodou em suas franjas os descontentes, mesmo que para isso a destruição criativa tenha levado os que não se adaptaram a desaparecer.

Em fins do século XX, principalmente após a redemocratização, inicia-se uma nova fase das relações capitalistas com o semiárido. Atraídas pela concessão de benefícios fiscais, diversas empresas passam a se mudar para a região, ao mesmo tempo em que o agronegócio se expande, principalmente na produção de frutas para a exportação, nos vales irrigados do semiárido e com a ampliação das áreas para a lavoura de soja no oeste da região, estabelecendo novas relações de trabalho no campo.

Essas empresas passam a explorar diretamente a mão de obra na região. Com o fim da Ditadura, que atuava forte no controle das massas trabalhadoras, e a efervescência do movimento sindical no Centro-Sul do país, a busca por um local com menos conflitos entre capital e trabalho levou ao deslocamento das plantas industriais para o território, estabelecendo uma média salarial bem mais baixa em comparação ao Centro-Sul.

A chegada de empresas de médio e grande porte e o consequente estabelecimento de novas relações entre capital e trabalho no semiárido e por todo o Nordeste estimulou, por sua vez, diversas mudanças no território. Dentre elas, podem ser citadas a atuação do Estado e, por consequência, das políticas públicas no semiárido. O paradigma de combate às secas começa a ser desestimulado em prol de políticas voltadas à convivência com o semiárido. Afinal, "[...] o conceito de que obras de engenharia seriam a solução para os problemas do Nordeste seco foi superado pelos próprios acontecimentos. Hoje, o semiárido nordestino tem milhares de açudes, e a fome, a sede, a miséria, enfim, o flagelo são os mesmos das secas do período colonial" (GARCIA, 1999, p. 74). 
A convivência com o semiárido é colocar em prática um novo olhar sobre o Nordeste, valorizando as potencialidades do território e de seus habitantes. A atuação, numa perspectiva de convivência com o semiárido, precisa identificar "[...] quais as competências que existem e que podem, a partir de ações especificas, transformar e consolidar o semiárido como uma região capaz de se integrar a dinâmica econômica do país” (QUEIROZ, 2009, p. 134).

Para Barbosa et al. (2018), a convivência com o semiárido é um paradigma de resistência, pois evita se alinhar com o modelo de desenvolvimento hegemônico na busca de uma lógica própria de desenvolvimento regional. No entanto, ressaltam os autores, embora tenha uma perspectiva progressista, o paradigma precisa avançar para uma proposta emancipatória que possa ir além do capital, para que os trabalhadores do semiárido consigam ter assegurados qualidade de vida, acesso à educação, terra, saúde e demais direitos.

\section{CAPITALISMO PARA O SEMIÁRIDO}

O território semiárido brasileiro é o maior do mundo em extensão e em população. Cerca de 21 milhões de habitantes moram nos mais de 900 mil quilômetros quadrados, que perpassam os estados do Ceará, Piauí, Rio Grande do Norte, Paraíba, Pernambuco, Alagoas, Sergipe, Bahia e o Norte de Minas Gerais (SILVA, 2016). Um território de grande extensão e com uma população considerável, que demanda a formulação de políticas públicas complexas para que possam dialogar em uma dimensão tão ampla.

Além disso, é preciso considerar o fato de que o Nordeste é a região brasileira com o maior número de pobres (SILVA, 2016), portanto, faz-se necessário valorizar “[...] as lutas e as conquistas do povo desta região diante do desafio de viver em um lugar estereotipado historicamente de inviável” (PEREIRA, 2013, p. 116). Como já observado neste trabalho, esse estereótipo atende os interesses das diversas elites locais e nacionais. Já é hora de uma nova construção, de uma nova identidade para o Nordeste e o semiárido.

Ao falar de capitalismo para o Semiárido, não se quer dizer que o território não era capitalista, e sim o fato de que existem diferentes estágios do capitalismo, coexistindo, ao mesmo tempo, em diversas sociedades (FRASER; JAEGGI, 2020). Assim, se há no Brasil 
regiões com capitalismo avançado, há outras onde este ainda não assumiu o mesmo grau de dinamismo. Por isso, existem pressões do sistema para avançar sobre essas regiões em seu ímpeto constante por mais valor, pois as regiões desenvolvidas e subdesenvolvidas estabelecem relações em que "[...] as regiões mais desenvolvidas extraem para si um dinamismo ainda maior, reduzindo como contrapartida o dinamismo das regiões menos desenvolvidas" (SAVIANI, 2013, p. 91).

O semiárido passa a ser visto de forma diferente por conta das constantes pressões do capital por expansão. Esse novo ciclo de expansão mundial do capitalismo, como observa Ianni (2011), desestrutura os projetos econômicos nacionais ao desconsiderá-los, interessado em uma integração regional que, acima de tudo, atenda a seus interesses e demandas. Ainda nas últimas décadas do século XX, na tentativa de construir uma nova identidade para o semiárido, buscou-se atrair novos elementos para o território que atendessem os preceitos do sistema capitalista, entendendo que apenas a submissão à lógica do capital poderia trazer a modernidade e o progresso necessários ao território.

Para Marx (2017), para que o sistema capitalista possa se estabelecer, faz-se necessário retirar os meios de trabalho dos trabalhadores e transformar em capital os meios de subsistência e de produção. Tal processo tem se efetuado no semiárido, por meio da desestruturação da agricultura familiar, que força os trabalhadores rurais a migrarem para as cidades. Nestas, os artesãos são impedidos de manter suas atividades, diante da concorrência dos produtos industrializados, lançados no mercado a preços mais baixos.

Farias (2012) explica que, no semiárido, a agricultura familiar era praticada em terras cedidas em regime de parceria pelos coronéis e chefes políticos locais aos aliados políticos, contribuindo para dominação econômica e política da elite sobre os trabalhadores. A história do semiárido é marcada por essas relações entre os chefes políticos, que controlavam o acesso a terra, e os agricultores. O autor destaca que o ritmo de vida dos sertanejos era ditado pela natureza, com os meses de trabalho agrícola iniciando a partir de janeiro, com as chuvas, e se prolongando até julho, com a colheita, com os camponeses realizando pouca ou nenhuma atividade produtiva nos meses restantes, à espera do reinício do ciclo. Em sua busca constante por valorização, é impensável ao capital tanto tempo sem trabalho e sem consumo. 
Era preciso separar esses trabalhadores dos meios de produção e subsistência, excluindo-os até mesmo dos recursos sociais comuns (FRAZER; JAEGGI, 2020).

Apenas “[...] a destruição da indústria doméstica rural pode proporcionar ao mercado interno de um país a extensão e a solidez exigidas pelo modo capitalista de produção" (MARX, 2017, p. 869). Depreende-se daí que a necessidade de expandir tanto a fronteira do consumo quanto a produção para o semiárido levaria à desorganização das relações de produção arcaicas existentes na região, com o consequente incentivo para trabalhadores venderem sua força de trabalho às indústrias e empreendimentos implementados na região sob as relações capitalistas.

Era preciso retirar "[...] ao trabalhador a propriedade de seus meios de trabalho, um processo que transforma em capital os meios sociais de subsistência e os de produção e converte em assalariados os trabalhadores diretos" (MARX, 2017, p. 836), abrindo caminho para a lógica capitalista no território. O semiárido deixa de ser percebido como um lugar improdutivo e passa a se inserir na lógica do capital, pois, afinal, o capitalismo “[...] possui um imperativo contínuo de explorar mais e mais terrenos para expropriar. Ele tem de buscar sempre novas bases não apenas de acumulação de capital, mas de possível despossessão" (FRAZER; JAEGGI, 2020, p. 61).

Assim, as áreas irrigadas e mais férteis são repassadas para grandes empresas de agronegócio, que atendem, principalmente, o mercado internacional. Amplamente mecanizada, a predominância dessas empresas resultou na dispensa de muitos agricultores e na desarticulação da agricultura tradicional.

A produção voltada para o mercado externo de frutas e outros produtos agrícolas tem aumentado ainda mais a fatia do agronegócio da região, uma vez que as grandes empresas agrícolas contam ainda com o apoio dos governos para garantir a segurança hídrica e estrutura logística. $\mathrm{O}$ artesanato, outra atividade econômica tradicional, vem sendo transformado pela expansão do capital para o semiárido, como as tradicionais imagens de santos do Cariri, por exemplo. Neto (2009) registra que os romeiros que visitam a região agora têm a opção de adquirirem a imagem do Pe. Cícero em resina:

$\mathrm{Na}$ base da escultura, a surpreendente informação: Made in China. Um jovem comerciante chinês (...) foi quem descobriu o filão. Manda fabricar milhões de 
exemplares em seu país natal e os importa em grandes contêineres pelo porto de Pécem, a cerca de sessenta quilômetros de Fortaleza. Veio também (...) um dos produtos que passaram a ser sonho de consumo de todo romeiro: outra estatueta do Padre Cícero em resina, mas que brilha no escuro, por causa de um cristal cravejado por 30 mil pontos de raio laser (NETO, 2009, p. 520).

Essa concorrência força os artesãos a buscarem novas ocupações ou se colocarem em nichos de mercado, onde acabam por se adaptar ao padrão do capital. Artífices em couro, joias, metais e outros materiais passam a se organizar em cooperativas que, na prática, instauram relações assalariadas entre os chefes das oficinas, cujos nomes atraem os consumidores e os demais artesãos. Antunes (2015) observa que a competitividade intercapitalista implica a desmontagem de parques industriais, mas a mesma também pode, como observado no caso dos artesãos do Cariri, desmontar as redes econômicas locais.

Marx (2017) esclarece que o que impele o capitalismo é a maior expansão possível do capital, ou seja, a maior exploração possível da força de trabalho. Ou seja, a expansão do capital não é para responder as demandas por integração ou melhores condições de vida das populações do semiárido, mas para conseguir a ampliação máxima da produtividade do trabalho e o aumento da exploração da força de trabalho.

Retiradas as condições de produção desses camponeses, muitas vezes pela dificuldade de acesso ao financiamento das plantações e/ou pela ausência de políticas públicas voltadas para os pequenos agricultores, tem-se farta oferta de mão de obra barata para as indústrias que se instalam na região. Aqui se percebe um problema crucial da industrialização do Nordeste, que é "[...] definir o tipo de industrialização capaz de gerar um verdadeiro desenvolvimento, pois sabemos de experiência que a tendência natural é favorecer indústrias sem qualquer vínculo direto com o mercado regional” (FURTADO, 2009, p. 25).

Para Furtado (2009), como as primeiras fábricas nordestinas foram pensadas como simples prolongamento das indústrias do Centro-Sul, acabaram por se estruturar de acordo com a demanda dessa região, resultando em maior concentração de renda e agravação das disparidades sociais no Nordeste, ao forçar a adaptação deste aos padrões de consumo da região mais rica.

Por isso, apesar da instalação de indústrias ter se iniciado nos anos 1960, como as mesmas estavam voltadas para o eixo Sul-Sudeste, apenas nos anos 1990 os elementos que consolidam a economia de mercado são incorporados no semiárido (PEREIRA JR., 2003). 
Atraídas pela concessão de benefícios fiscais, diversas plantas industriais passam a se fixar na região, ao mesmo tempo em que a produção de frutas para a exportação efetiva, a expansão do agronegócio, estabelecendo novas relações de trabalho no campo.

Muitos dos novos negócios que se instalam no semiárido vêm de outras regiões do país, atraídos pelos incentivos fiscais e pela mão de obra mais barata e sem experiência sindical, o que facilita o estabelecimento de condições de exploração mais duras. Uma análise do setor calçadista, que durante os anos 1990 e 2000 consolida a transferência de grandes plantas industriais para o Nordeste, mostra que “[...] a busca por redução de custos foi certamente um dos motivos que levaram ao deslocamento de fábricas para o Nordeste, onde se destacam os estados do Ceará e da Bahia” (SANTOS et al., 2002, p. 67).

Certamente, a mão de obra de menor custo e em grande quantidade foi um dos fatores que mais influenciaram a migração das fábricas do Centro-Sul do país para o Nordeste. As empresas, principalmente as que se dedicam à produção de mercadorias de baixo valor agregado e que utilizam intensivamente a mão de obra, têm sua competitividade afetada quando a variável salário apresenta um peso considerável em sua planilha de custos (SANTOS et al., 2002, p. 74-75).

Santos et al. (2002) corroboram com o exposto ao afirmarem que os custos de mão de obra, no Brasil, giram em torno de 15\% da produção, enquanto no Nordeste, mesmo sem os benefícios fiscais, ficam em torno de 10\%. Os autores complementam:

\footnotetext{
Enquanto a indústria de calçados no Nordeste paga em média um salário mínimo ao trabalhador de "chão de fábrica", por exemplo, na região do Vale dos Sinos paga-se entre dois e 2,5 salários mínimos. A diferença tende a se ampliar quando se considera a formação de cooperativas de trabalho, um modo de subcontratação de mão-de-obra com o objetivo de evitar o pagamento de encargos trabalhistas (SANTOS ET ALL, 2002).
}

Isso apenas demonstra que, apesar de o capitalismo se erigir sobre a suposição de que os trabalhadores são livres e iguais (FRAZER; JAEGGI, 2020), na verdade, o sistema capitalista se realiza por meio da exploração das diferenças que ele mesmo cria entre os trabalhadores. Enquanto os trabalhadores do interior semiárido estão livres do acesso aos meios de subsistência e produção, devendo trabalhar por valores mais baixos do que os de outras regiões, caso desejem obter os meios de vida necessários a si e a suas famílias; os 
trabalhadores de onde as fábricas vieram têm a liberdade de ficar desempregados, já que seus empregos se foram junto com a planta industrial transferida para o Nordeste.

A proletarização das populações nordestinas é um processo que "[...] envolve um conjunto de coerções e apropriações de capacidades, relações sociais, conhecimentos, hábitos de pensamento e crenças pré-capitalistas da parte dos que são proletarizados" (HARVEY, 2005, p. 122). Um processo que demanda educação, já que “[...] a questão educacional está ligada ao modo de produzir a nossa existência material” (SILVA; MACIEL; SOUZA, 2019, p. 161). Uma educação que se limita ao básico necessário para a operação do trabalhador, sendo, portanto, ministrada em uma perspectiva parcial e não integral. Apesar do atraso em relação às regiões do capitalismo mais avançado, o Nordeste vivencia, em termos de educação, as mesmas condições dos demais trabalhadores onde "[...] a contínua ampliação da exploração dos trabalhadores, a precarização das relações de trabalho e a diminuição, por conta do avanço da informática, dos conhecimentos necessários para operar os meios de produção resultaram em relegar a educação em simples capacitação do trabalhador" (SILVA; MACIEL; SOUZA, 2019, p. 153).

$\mathrm{Na}$ verdade, como bem notou Fernandes (2008), ao se referir a modo de produção, a terminologia marxista "[...] implica todo um complexo sociocultural, extremamente típico e variável; compreende as noções de forma social e de conteúdo material em sua correspondência efetiva" (FERNANDES, 2008, p. 34). Ao falar de modo de produção, é preciso ter em mente: as forças materiais de produção, o sistema de relações sociais e o sistema de padrões de comportamento e suas interações entre si, bem como com o sistema social. Então, quando se pensa na integração do Nordeste e do semiárido ao sistema capitalista, não se pode deixar de observar a sociedade como um todo, não se limitando a uma única dinâmica, como a economia, acreditando ser esta que determina toda a sociedade (FRASER; JAEGGI, 2020).

Apesar das mudanças descritas, e com a firme presença das relações capitalistas no território, o Nordeste " [...] continua a desafiar o Brasil ao se manter o grande hiato existente entre seus padrões de vida e os do Sudeste, Sul e Centro-Oeste" (ARAÚJO, 2009, p. 40). A elite e não o conjunto da população se apropria dos investimentos públicos e privados, confirmando que o crescimento econômico observado na região "[...] funda-se na 
preservação dos privilégios das elites que satisfazem o seu afã de modernização" (FURTADO, 2009, p. 26).

\section{CONCLUSÃO}

Diante do exposto, nota-se a necessidade de realizar uma reconstrução de valores e princípios de forma a reformular as prioridades que orientam a relação do nordestino entre si e com restante do país. Fruto, como já colocado aqui, de uma invenção, é preciso que a formulação da ideia de Nordeste possa avançar, abandonando as concepções elitistas e excludentes e construir um novo Nordeste que esteja a serviço das classes desfavorecidas, sendo importante, para isso, reforçar o desenvolvimento do acesso a direitos que historicamente têm sido negados a essa gente, permitindo o acesso à cidadania. Por isso, a premente necessidade de se constituir no semiárido uma proposta de que supere a dicotomia entre os dois paradigmas atuais, o de combate às secas e o de convivência com o semiárido.

O avanço do agronegócio e da industrialização, o surgimento de novas formas de entretenimento e o estímulo ao consumo têm realizado em todo o semiárido, como em tantos outros locais onde se efetivam as relações capitalistas de produção, a ampliação das desigualdades e o consequente aumento da violência e da criminalidade. O capital não consegue absorver tantos trabalhadores deserdados de suas antigas funções sociais e nem dar solução aos problemas sociais que surgem na esteira de sua lógica.

A maior urbanização do território, advinda com as novas relações de produção e de sociabilidade, estimulou a demanda por serviços, como educação, saúde e segurança, que o Estado não consegue atender, e a iniciativa privada o faz de maneira deficiente, pois os lucros dessa exploração ainda não compensam os custos. Integrar o semiárido à economia brasileira, reproduzindo a lógica do mercado, apenas efetiva a exploração do trabalhador. A convivência com o semiárido não será efetivada sem romper com o sistema capitalista. Substituir a dominação das oligarquias pela do mercado não resolve a situação de exploração e as opressões a que estão submetidos os trabalhadores nordestinos.

Para superar, de fato, a exploração de seu povo e as desigualdades próprias da lógica capitalista, é preciso desenvolver uma lógica superior à do capital, pois diante da “[...] 
impossibilidade orgânica de o homem desenvolver-se plenamente no capitalismo, bem como da necessária afirmação da possibilidade de o homem desenvolver-se em todas as suas potencialidades" (SILVA, 2006), não se pode permanecer nas estreitas faixas de atuação que o capitalismo deixa escapar de seus domínios.

Esse é um processo que envolve a educação em todos os níveis, os movimentos sociais, culturais, porque, se, por um lado, o aprofundamento das relações capitalistas de produção rompe com algumas práticas de dominação arcaicas das oligarquias da região, os problemas advindos de um sistema que mercantiliza a vida inviabilizam uma verdadeira emancipação das mulheres e homens do território.

\section{Referências}

ALBUQUERQUE JR, Durval Muniz. A invenção do Nordeste e outras artes. São Paulo: Cortez, 2011.

ANTUNES, Ricardo. Adeus ao trabalho? Ensaio sobre as metamorfoses a centralidade do mundo do trabalho. São Paulo: Cortez, 2015.

ARAÚJO, Tânia Bacelar. Desenvolvimento regional do Brasil. In: O pensamento de Celso Furtado e o Nordeste hoje. Rio de Janeiro: Contraponto; Centro Internacional Celso Furtado de Políticas Públicas para o desenvolvimento; Banco do Nordeste, 2009.

BALDIJÃO, Carlos Eduardo; TEIXEIRA, Zuleide Araújo. A educação no governo Lula. São Paulo: Editora Fundação Perseu Abramo, 2011.

BAPTISTA, Naidison de Quintella; CAMPOS, Carlos Humberto. Educação contextualizada para a convivência com o semiárido. In: Convivência com o Semiárido Brasileiro: Autonomia e Protagonismo Social. Irio Luiz Conti e Edni Oscar Schroeder(org). Brasília-DF: Fundação de Apoio da Universidade Federal do Rio Grande do Sul - FAURGS/ REDEgenteSAN / Instituto Brasileiro de Desenvolvimento e Sustentabilidade - IABS / Agência Espanhola de Cooperação Internacional para o Desenvolvimento - AECID / Ministério do Desenvolvimento Social e Combate à Fome MDS / Editora IABS, 2013.

BARBOSA, Erlene Pereira; MACIEL, Paulo Henrique Freitas; SOUSA, Ana Carmita Bezerra de; SILVA, Wagner Pires da. Relações capitalistas no semiárido: uma nova fronteira de expansão do capital. In: IV Semana de Economia Política - Os Desafios do Brasil para o século XXI: Economia, sociedade e Meio Ambiente. Viès, 2018. Anais (online). Fortaleza: Viès, 2018. Disponível em https://viessep.wixsite.com/semanaeco2018/anais. Acessado em 02/08/2021. 
BUARQUE, Cristovam. Nordeste: Quinhentos anos de descobertas. In: Brasil: um século de transformação. Org.: Ignacy Sachs, Joge Wilheim e Paulo Sérgio Pinheiro. São Paulo: Companhia das Letras, 2001.

FARIAS, Airton de. História do Ceará. Fortaleza: Armazém da Cultura, 2012.

FERNANDES, Florestan. Introdução. In: Contribuição à crítica da Economia Política. São Paulo: Expressão Popular, 2008.

FRAZER, Nancy; JAEGGI, Rahel. Capitalismo em debate: uma conversa na teoria crítica. São Paulo: Editora Boitempo, 2020.

FURTADO, Celso. O Nordeste: reflexões sobre uma política alternativa de desenvolvimento. In: $\mathbf{O}$ pensamento de Celso Furtado e o Nordeste hoje. Rio de Janeiro: Contraponto / Centro Internacional Celso Furtado de Políticas Públicas para o desenvolvimento / Banco do Nordeste, 2009.

GARCIA, Carlos. O que é Nordeste brasileiro. São Paulo: Editora Brasiliense, 1999.

HARVEY, David. O Novo Imperialismo. São Paulo: Ed. Loyola, 2005.

IANNI, Octavio. Capitalismo, violência e terrorismo. Rio de Janeiro: civilização Brasileira, 2004.

MARX, Karl. Para a crítica da economia política. São Paulo: Nova Cultural, 1986.

MARX, Karl. O capital. Rio de Janeiro: Civilização Brasileira, 2017.

MENEZES, Djacir. O outro Nordeste. Fortaleza: Expressão Gráfica e Editora, 2018.

NETO, Lira. Padre Cícero: poder, fé e guerra no sertão. São Paulo: Companhia das Letras, 2009.

PEREIRA, Eugênia da Silva. Educação contextualizada e convivência com o semiárido: lutas, conquistas e desafios. In: Convivência com o Semiárido Brasileiro: Autonomia e Protagonismo Social. Irio Luiz Conti e Edni Oscar Schroeder(org). Brasília-DF: Fundação de Apoio da Universidade Federal do Rio Grande do Sul - FAURGS/ REDEgenteSAN / Instituto Brasileiro de Desenvolvimento e Sustentabilidade - IABS / Agência Espanhola de Cooperação Internacional para o Desenvolvimento - AECID / Ministério do Desenvolvimento Social e Combate à Fome - MDS / Editora IABS, 2013.

PEREIRA JUNIOR, Edilson Alves. Espaço, industrialização e acumulação capitalista: uma abordagem para o Nordeste e o Ceará. In: Mercator: Revista de Geografia da UFC. 
Fortaleza, Ano 02, Nº 04, p. 65 -76, 2003. Disponível em

http://www.mercator.ufc.br/mercator/article/view/151/120. Acessado em 22/07/2021.

QUEIRÓZ, Manuel Abílio de. Semiárido brasileiro: uma análise das potencialidades e das competências para seu desenvolvimento. Parcerias Estratégicas. Brasília/DF, v.14, n.29, p.129-144, jul./dez. 2009.

SANTOS, Angêla Maria Medeiros M.; CORRÊA, Abidack Raposo; ALEXIM, Flávia Menna Barreto; PEIXOTO, Gabriel Barros Tavares. Deslocamentos de empresas para os estados do Ceará e da Bahia: o caso da indústria calçadista. BNDES Setorial. Rio de Janeiro, n. 15, p. 63-82, mar. 2002. Disponível em https://web.bndes.gov.br/bib/jspui/handle/1408/2599?mode=full. Acessado em $15 / 07 / 2021$.

SAVIANI, Dermeval. Educação: do senso comum à consciência filosófica. Campinas/SP: Autores Associados, 2013.

SILVA, Roberto Marinho Alves da. Entre dois paradigmas: combate à seca e convivência com o semiárido. In: Sociedade e Estado. Brasília, v. 18, n. 1/2, p. 361-385, jan./dez. 2003. Disponível em https://www.scielo.br/j/se/a/P7t9S99gxSqYsNbSDVHLc9k/abstract/?lang=pt. Acessado em 02/08/2021.

SILVA, Antonia Almeida. Democracia e democratização da educação: primeiras aproximações a partir da teoria do valor. In: A teoria do valor em Marx e a educação. São Paulo: Cortez, 2006.

SILVA, Wagner Pires; MACIEL, Paulo Herinque Freitas; SOUZA, Ana Carmita Bezerra. Educação e trabalho em tempos de precarização. In: Revista Germinal: Marxismo e Educação em Debate, Salvador, v. 11, n.1, p. 153-161, abr. 2019. Disponível em https://periodicos.ufba.br/index.php/revistagerminal/article/view/27688. Acessado em 10/08/2021.

SILVA, Wagner Pires da. As ações de extensão na construção de uma universidade sertaneja. 2016. 135f. Dissertação (Mestrado) - Universidade Federal do Ceará, Fortaleza, 2016.

Trabalho oriundo do I Seminário do GPOSSHE - Educação do campo e Pedagogia bistórico-crítica em contexto de crise e pandemia 